\title{
Introduction: Pharmacy Reimbursement
}

\author{
Bonnie C. Greenwood, PharmD, BCPS
}

$\mathrm{T}$ his month's issue of the Journal of Managed Care E Specialty Pharmacy contains a collection of 5 perspectives addressing the issue of community pharmacy reimbursement. While not a new topic, this group of authors renew the call for change. Each author provides context for challenges with the current pharmacy reimbursement system from their individual perspective and then outlines potential solutions to change the system so that it empowers the profession of pharmacy to improve lives for patients across the country.

To kick off this series, Brian Nightengale outlines the core function of community pharmacy in supporting the health of patients and their communities. In recalling how the industry changed over the past several decades and put major downward financial pressure on community pharmacies, especially independent retailers, he calls on the health care system to recognize and support the role of the community pharmacy in optimizing patient outcomes.

In his perspective piece, Troy Trygstad highlights how pharmacists are stewards of one of the most cost-effective forms of health care: prescription medications. The profession of pharmacy needs to be a mandatory part of the value equation as this health care system evolves. However, we have done little to help ourselves get there. Trygstad argues that if pharmacy does not claim our role in improving outcomes in our communities now, we may lose that opportunity forever. Accountable pharmacy organizations and collaboration between managed care pharmacy and community pharmacy may be what gets us there.

From the pharmacy benefit manager (PBM) perspective, Patty Taddei-Allen explains why PBMs should stop considering drugs as purely a commodity, racing to get the lowest price. Rather, PBMs should look to community pharmacy as their partners in the provision of value-added services for patients. Echoing Nightengale, she underlines this need by pointing to the future that will have fewer physicians, more patients, and a very capable, yet underutilized, pharmacy profession.

Michael Stull and Cristy Gupton provide a perspective from the employer and plan sponsor. While pharmacy-related reimbursement change is happening, the truth is that employers are

Copyright $\odot 2020$, Academy of Managed Care Pharmacy. All rights reserved. challenged to balance long-term health benefits with short-term health care costs. In some cases, pharmacy is missing the boat, as employers leverage disease management programs offered by medical providers when they could be provided by community pharmacies. Some of the employers who are changing this paradigm are doing so by simply picking a place to start, finding willing pharmacy and provider partners in their local areas, and leaning into the iterative nature of process.

To round out this series, Michael Rupp takes us back to basics. He makes the case that while new models are important to pursue, the issue of how we pay pharmacists for conventional dispensing-related services is getting missed in the conversation. His piece unpacks the history of our current reimbursement system, highlighting the role that managed care pharmacy plays in driving down ingredient costs. His solution starts with creating a set of accurate metrics to measure quality of medication dispensing, prospective drug utilization review, and counseling and then rewarding those pharmacies that consistently meet higher standards.

As managed care pharmacists, we have a responsibility to our patients and our profession. For years we have worked with our community pharmacy partners to ensure that patients have access to cost-effective care, although admittedly at times our goals have been at odds. The variety of perspectives provided in this series shows that there is abundant opportunity for managed care and community pharmacy to work together and elevate our profession to fully embrace the role we are meant to play.

\section{Author}

BONNIE C. GREENWOOD, PharmD, BCPS, Clinical Program Director and Assistant Professor, University of Massachusetts Medical School - Commonwealth Medicine, Shrewsbury.

AUTHOR CORRESPONDENCE: Bonnie C. Greenwood, PharmD, BCPS, University of Massachusetts Medical School - Commonwealth Medicine, 333 South St., Shrewsbury, MA 01545-2732.

Tel.: 774.455.3198; E-mail: Bonnie.Greenwood@umassmed.edu.

\section{DISCLOSURES}

No funding supported the writing of this article. The author has nothing to disclose 